\title{
Effect of Buffer Solutions on the Flow and Fracture in Calcite
}

\section{S.O.O. Olusunle ${ }^{* 1}$, W.O. Siyanbola ${ }^{2}$, A.R. Adetunji ${ }^{3}$, M.O.Adeoye ${ }^{3}$ and O.O. Adewoye ${ }^{1}$}

1. National Agency for Science and Engineering Infrastructure, NASENI, Abuja, Nigeria

2. Centre for Energy Research and Development, Obafemi Awolowo University, Ile-Ife, Nigeria 3. Materials Science and Engineering Dept., Obafemi Awolowo University, Ile-Ife, Nigeria

\author{
*e-mail:tolusunle@yahoo.co.uk
}

\begin{abstract}
$K_{l} c$ Values that are environment - sensitive were obtained. Flow and fracture resulting from Vickers indentation testing of $\{100\}$ have been studied. Plastic flow occurred in calcite; they are anisotropic and environment - sensitive. Fracture in calcite occurred in lateral, median, and subsurface models. Meyer's indices were determined and they also are environment - sensitive, they were found to be $n<2$.
\end{abstract}

KEYWORDS: Vickers indentation; flow and fracture; Meyer's index; environment-sensitive; anisotropy.

\section{INTRODUCTION}

Microindentation technique has been used by various authors to study near-surface deformation behaviour of ceramic materials, using Vickers or Knoop indentor by applying low loads [1-4]. However, fracture toughness, often perceived as the limiting factor for ceramics applications, is being improved to make ceramics competitive as engineering materials. It has been reported that flaws that cause fracture of ceramic materials are smaller than $50 \mu \mathrm{m}$ in most cases [4].

Quenching temperature has been found to affect the microhardness of rhombohedral single crystal when studies were carried out on freshly cleaved crystal surfaces of calcite [5]. 
Etch-pit morphology has also been studied on calcite cleavages by using different concentrations of glacial acetic acid; where it is found that lateral reaction rates are less at high concentrations as well as low concentrations of glacial acetic acid [6].

The aim of this work is to estimate $K_{1 c}$ for calcite in the media (buffer solutions $\mathrm{Na}_{2} \mathrm{HPO}_{4} / \mathrm{NaH}_{2} \mathrm{PO}_{4}$ ) at room temperature; to investigate the anisotropy of microhardness (hence $\mathrm{K}_{1 \mathrm{c}}$ ) in the media; to estimate the Meyer indices, and finally to study the flow and fracture as they occur in calcite.

\section{EXPERIMENTAL DETAILS}

Calcite samples from Igbeti in south-western Nigeria, were annealed in a micro-furnace at $480^{\circ} \mathrm{C}$ (753K) for 5 hours in air. This was undertaken to minimise error in the analysis of the material due to intrinsic and extrinsic defects.

Vickers indentation experiments were undertaken in air and in the phosphate $\left(\mathrm{Na}_{2} \mathrm{HPO}_{4} / \mathrm{Na}_{2}\right.$ $\mathrm{HPO}_{4}$ ) buffer solutions, at room temperature.

The indentation load was varied in this order: $0.01 \mathrm{~N}, 0.015 \mathrm{~N}, 0.020 \mathrm{~N}, 0.025 \mathrm{~N}, 0.030 \mathrm{~N}$ and $0.035 \mathrm{~N}$; average indent sizes were recorded for each load. In order to obtain self consistency within a given experiment, the indentations were all made in one session using same indenter, and the indents were evenly spaced approximately twice the length of the diagonal [7].

The solutions were applied on the surface of the samples, and then the indentations were made. This was repeated for every indent.

Microhardness as a function of $\mathrm{pH}$ facilitates the investigation of the flow mobility or behaviour as a function of $\mathrm{pH}$ values referred to as chemomechanical effect $[8,9,10 \& 11]$.

Load as a function of indent size relationship, given as

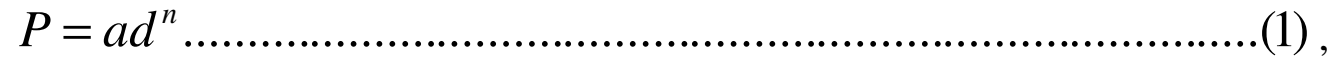

(where ' $a$ ' is a materials constant, $d$ is the indentation size and $n$ is the Meyer's index), reveals whether the material's hardness increases with decrease in load (i.e. when $n<2$ ), or that the hardness is load-independent (i.e. $\mathrm{n}=2$ ), or that hardness number increases with increase in load (i.e. $\mathrm{n}>2$ ). Grade II Gold ( $\mathrm{Au}$ ) was evaporated on the surface of the samples to enhance sharp and clear photomicrographs. 


\section{RESULTS AND DISCUSSION}

Microhardness numbers obtained from tests conducted on Beuhler Micromet microhardness tester by using a standard Vickers Diamond indenter with axis aligned along $<100>$ on the $\{100\}$ test surface can be presented as a Meyer's plot for each environment, or alternatively represented by equation (1) as shown above.

Vickers Hardness number decreased with increasing load (and indentation size) as is typical of ceramic materials [12]. This variation is large in Calcite as reflected in Table 1. The variation in $\mathrm{SiC}$ has been found to be $44.22 \mathrm{MPa}$ at $0.49 \mathrm{~N}$ to $38.33 \mathrm{MPa}$ at $4.9 \mathrm{~N}$ in air [13]; that of Beryl is $12.29 \mathrm{MPa}$ at $0.49 \mathrm{~N}$ to $11.47 \mathrm{MPa}$ at $4.9 \mathrm{~N}$ also in air [13].

Table 1. pH Dependence of $\mathrm{K}_{1} \mathrm{c}$ in Calcite.

\begin{tabular}{|l|c|c|c|c|c|c|}
\hline \multicolumn{1}{|c|}{ Environment } & Air & $\mathrm{pH} 6.5$ & $\mathrm{pH} \mathrm{7.0}$ & $\mathrm{pH} \mathrm{7.5}$ & $\mathrm{pH} 8.5$ & $\mathrm{pH} 8.8$ \\
\hline $\mathrm{P}=a d^{n}$ & $0.0642 \mathrm{~d}^{1.808}$ & $0.0722 d^{1.807}$ & $0.1496 d^{1.629}$ & $0.1405 \mathrm{~d}^{1.555}$ & $0.1183 \mathrm{~d}^{1.625}$ & $0.1226 \mathrm{~d}^{1.633}$ \\
\hline $\mathrm{VHN}(0.10 \mathrm{~N})$ & $319 \mathrm{GPa}$ & $53.5 \mathrm{GPa}$ & $46.5 \mathrm{GPa}$ & $49.9 \mathrm{GPa}$ & $129.4 \mathrm{GPa}$ & $62.4 \mathrm{GPa}$ \\
\hline $\mathrm{VHN}(0.35 \mathrm{~N})$ & $87.5 \mathrm{GPa}$ & $30.3 \mathrm{GPa}$ & $26.3 \mathrm{GPa}$ & $31.0 \mathrm{GPa}$ & $40.1 \mathrm{Gpa}$ & $28.3 \mathrm{Gpa}$ \\
\hline$(\mathrm{E} / \mathrm{H})^{1 / 2}$ & 8.9086 & 8.3600 & 7.5101 & 9.0120 & 8.7382 & 8.4198 \\
\hline $\mathrm{E}(\mathrm{GPa})$ & 54.11 & 54.11 & 54.11 & 54.11 & 54.11 & 54.11 \\
\hline $\mathrm{H}(\mathrm{GPa})$ & 0.6818 & 0.7742 & 0.9593 & 0.6662 & 0.7086 & 0.7632 \\
\hline $\mathrm{K}_{1} \mathrm{c}\left(\mathrm{MPam}^{1 / 2}\right)$ & 0.0217 & 0.0088 & 0.0067 & 0.0094 & 0.0126 & 0.0095 \\
\hline
\end{tabular}

Flow and fracture patterns were observed and are environment sensitive. Pin-cushion indentation as observed in Figures 1d and 1f is indicative of irreversible deformation in Calcite, which had also been observed in Beryl tested in air [13].

It can now be deduced that (i) plastic flow occurs in calcite and is environment - sensitive and (ii) plastic flow in calcite is anisotropic as well, suggesting the existence of a well defined slip system, similar to the case of Beryl [13].

The above conclusion, emanating from the consequence of Sinking-in being associated with anisotropic flow [14], has been observed to manifest in the characteristic and observed pincushion effect $[14,15]$ in Figures $1 d$ and 1f.

Fracture in Calcite has occurred in the lateral and median model (Figures 1i, 1o and 1p), while incidence of sub-surface cracking is observed in Figure 1a, for example. Fracture rarely emanated from the indents except in Figures $1 \mathrm{j}$ and $1 \mathrm{e}$, but there are instances of fracture activity away from the indent (e.g. Figures $1 \mathrm{a}$ and $1 \mathrm{p}$ ). 


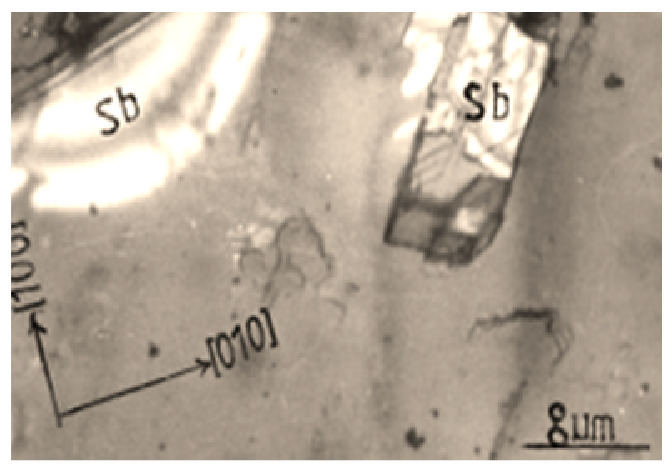

a

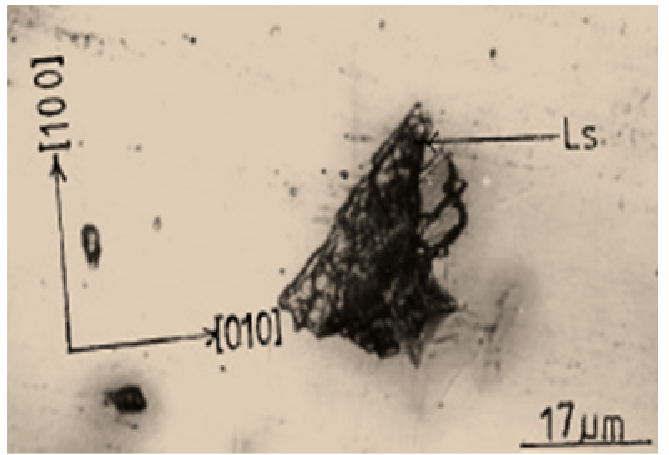

c

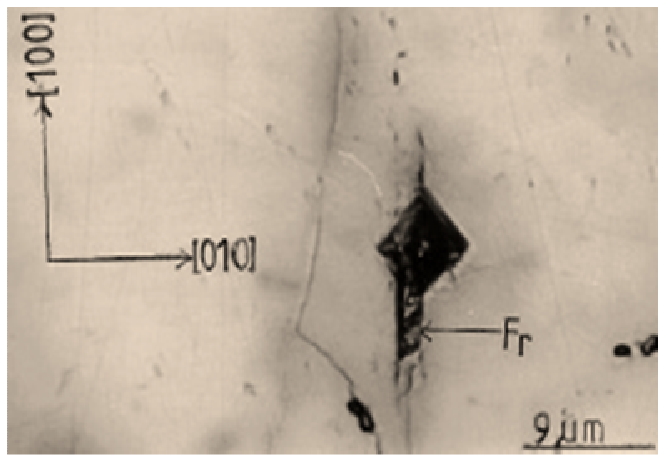

$\mathbf{e}$

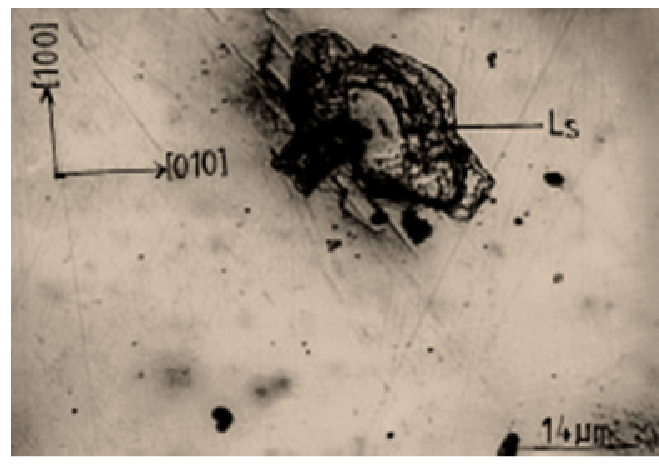

b

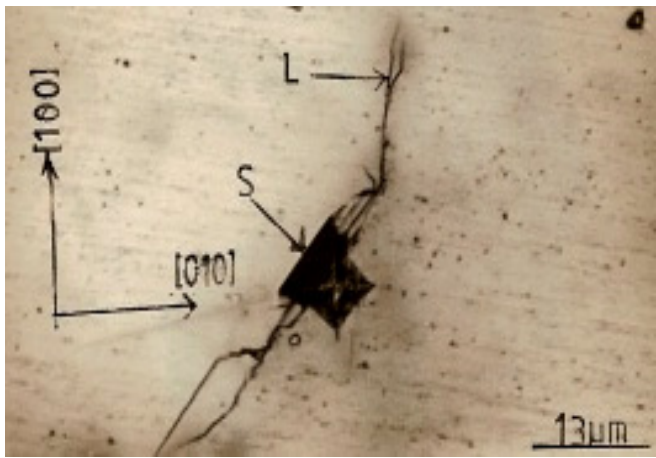

d

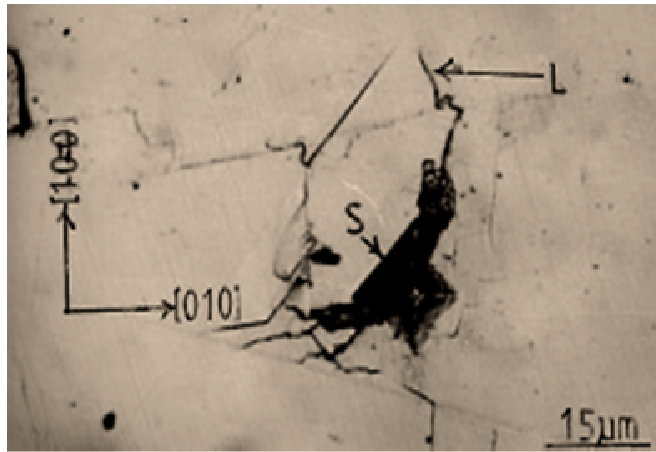

$\mathbf{f}$

Fig. 1 (a-p). Photomicrographs of cracks in Calcite. $\underline{a}$. Calcite in Air under-10gm load: Subsurface cracking (Sb): $\underline{\boldsymbol{b}}$. Calcite in PH 6.5 30gm load: Lateral Cracks stepped (Ls); $\underline{\boldsymbol{c}}$

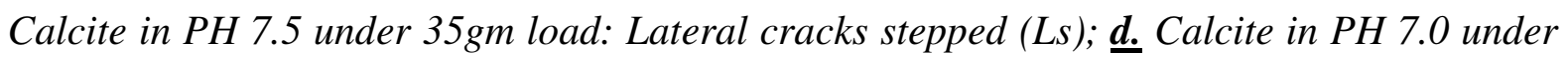
30gm load: Sinkin-in(S) and lateral cracks $(L)$; $\underline{e}$. Calcite in PH 8.8 under 15gm load; Fracture (Fr); f. Calcite in PH 8.8 under 30gm load; Lateral cracks (L) and Sinkin-in(S); 


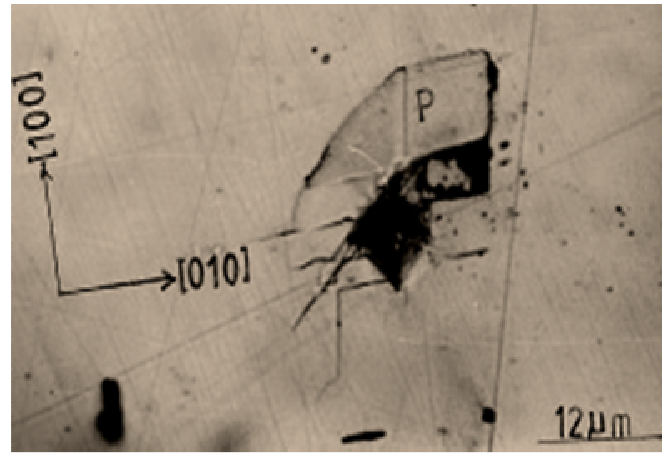

g

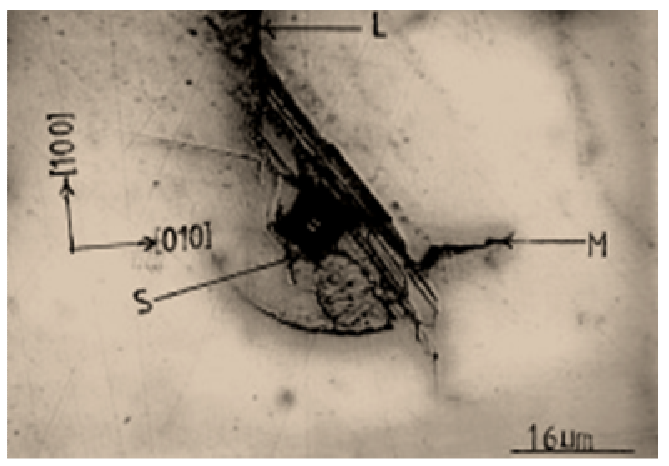

i

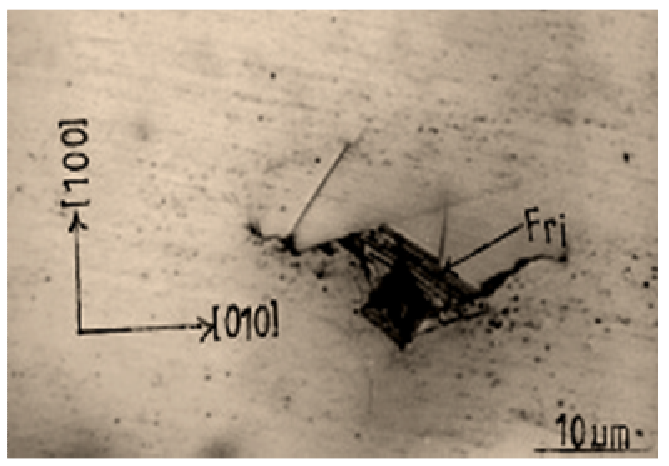

$\mathbf{k}$

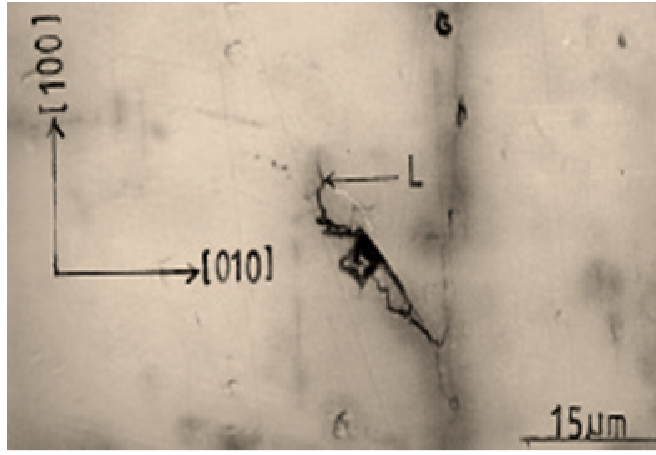

h

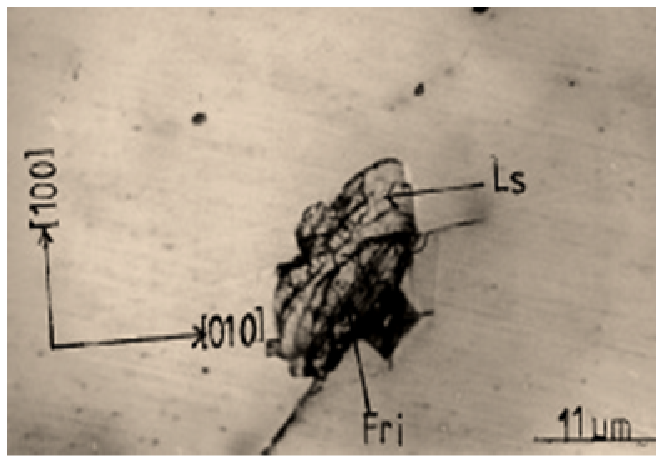

j

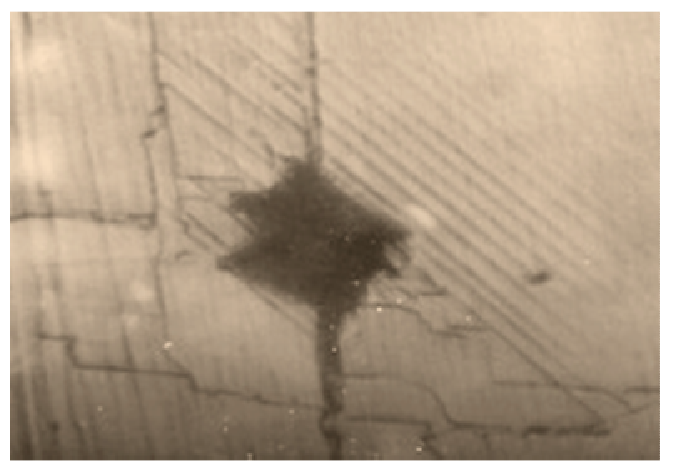

1

(Fig. 1, continued) g. Calcite in PH 8.5 under 20gm load; Peeling off effect due to interaction of lateral cracks with change in PH (P); $\underline{\boldsymbol{h}}$. Calcite in PH 8.5 under 30gm load;

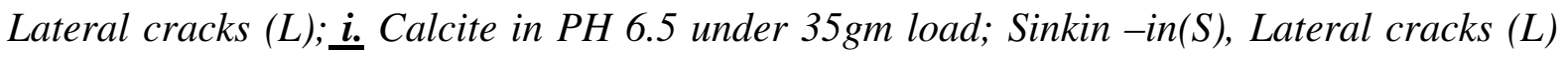
and medium cracks $(M) ; \dot{j}$. Calcite in PH 7.0 under 25gm load; Lateral cracks stepped (Ls) Parallel to test surface; $\underline{\boldsymbol{k}}$. Calcite in PH 7.0 under $30 \mathrm{gm}$ load; Fringes (Fri) that are anisotropic, which denotes cleavage; $\underline{\text { l. }}$ Calcite in Air under $15 \mathrm{gm}$ load; Flow pattern; 


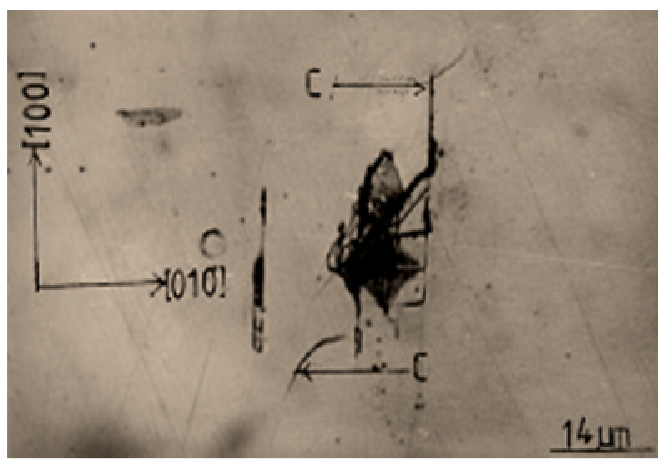

m

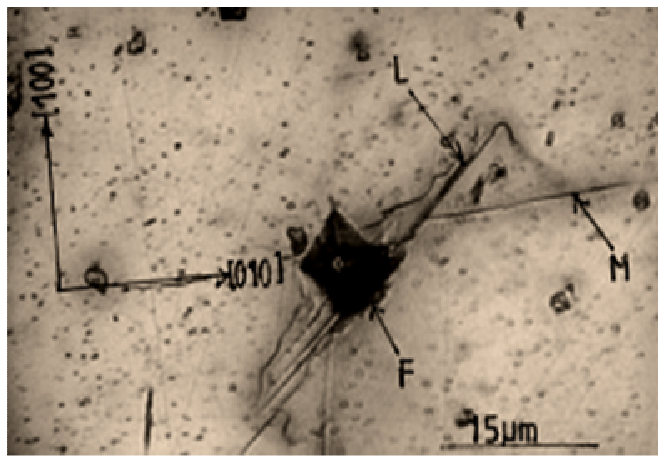

o

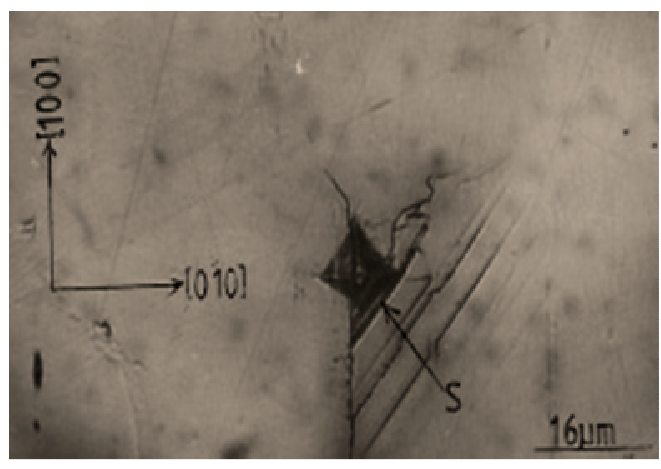

$\mathbf{n}$

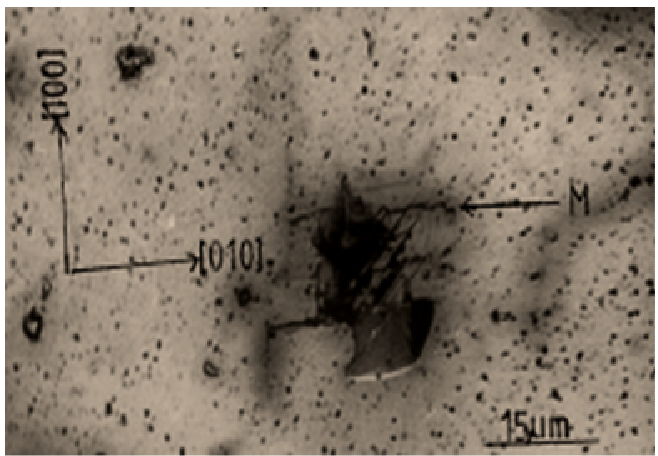

p

(Fig. 1, continued) $\underline{\boldsymbol{m}}$. Calcite in PH 8.5 under 25gm load; Cleavage direction(C) parallel to test surface $\underline{\boldsymbol{n}}$. Calcite in PH 8.8 under 35gm load; sinkin -in (S); $\underline{\text { o. }}$ Calcite in PH 8.8 under $30 \mathrm{gm}$ load; Lateral cracks $(L)$ medium cracks $(M)$, and Fringes $(F) ;$ p. Calcite in Air under $30 \mathrm{gm}$ load; Medium cracks (M).

A plot of $\mathrm{P} \mathrm{Vs} \mathrm{C}_{\mathrm{R}}{ }^{3 / 2}$ is given in Figure 2 as a function of increasing load and environment. From the relation

$$
K_{1} c=\frac{P}{C_{R}^{3 / 2}}\left[\zeta_{r}^{R} \operatorname{Cot}(\Psi)^{2 / 3}\right](E / H)^{1 / 2}
$$

Where $\zeta_{r}{ }^{R}$ is a constant evaluated to be $0.032 \pm 0.002, C_{R}$ is the radial crack length, the indenter cone half angle, $\psi=74^{\circ}$ for Vickers indenter, $K_{1} \mathrm{c}$ is the stress intensity factor, $(\mathrm{E} / \mathrm{H})$ is the ratio of Young's modulus to hardness which is reflected in Table 1, and the value of E is 54.11 Gpa [17]. 


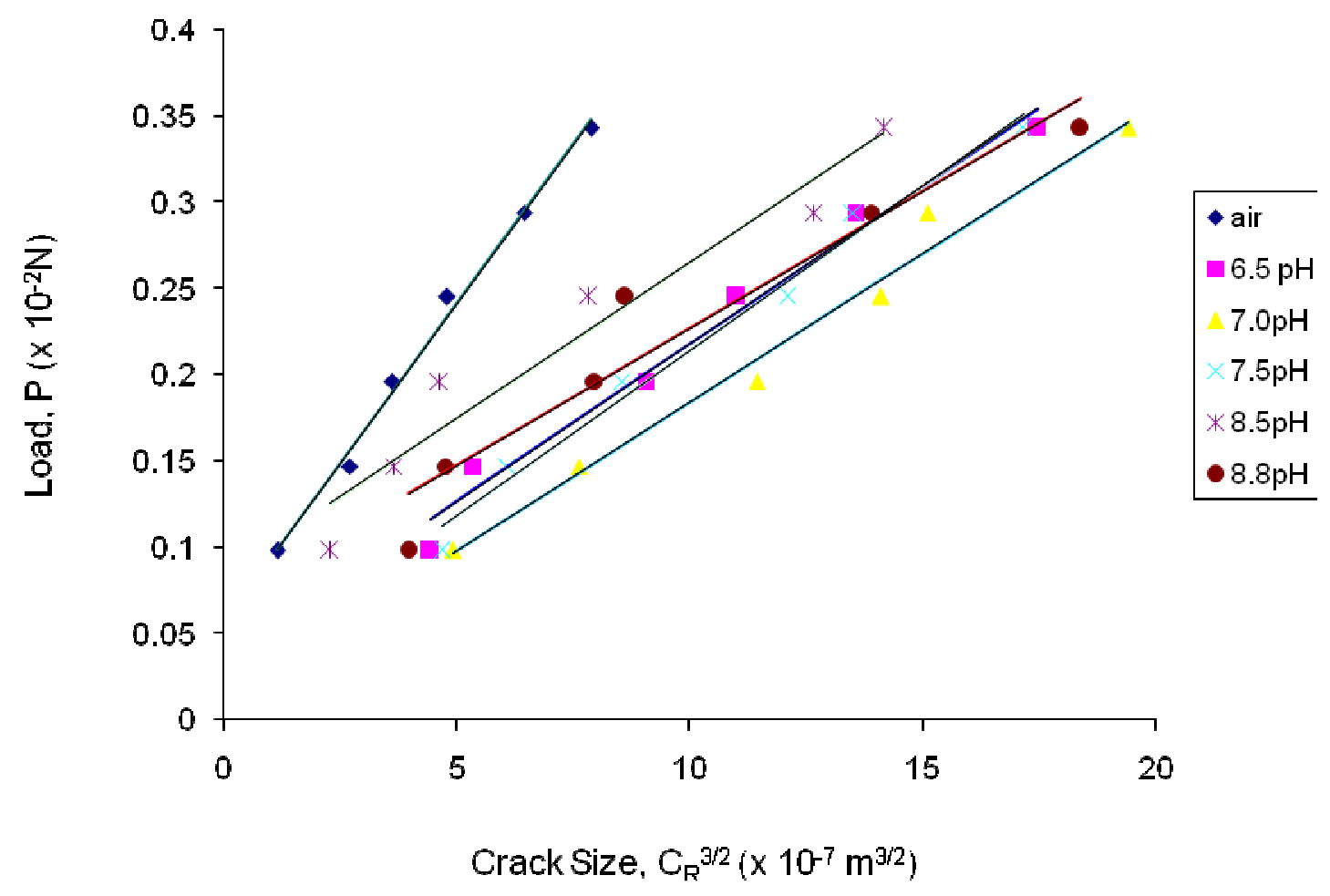

Fig. 2. Applied load $\mathrm{P}$ against crack parameter $\mathrm{C}_{\mathrm{R}}{ }^{3 / 2}$ as a function of environment.

Calcite was found to have maximum hardness at neutral $\mathrm{pH}$, while minimum hardness was observed at pH 7.5 (i.e. in basic medium), as shown in Figure 3. Further examination of Calcite in 2-Propanol and in air revealed that there is a definite orientation dependence of hardness in the former medium, denoting dislocation activity (Table 2, Figure 4), but the dependence is less marked in air, in the trigonal Calcite. 


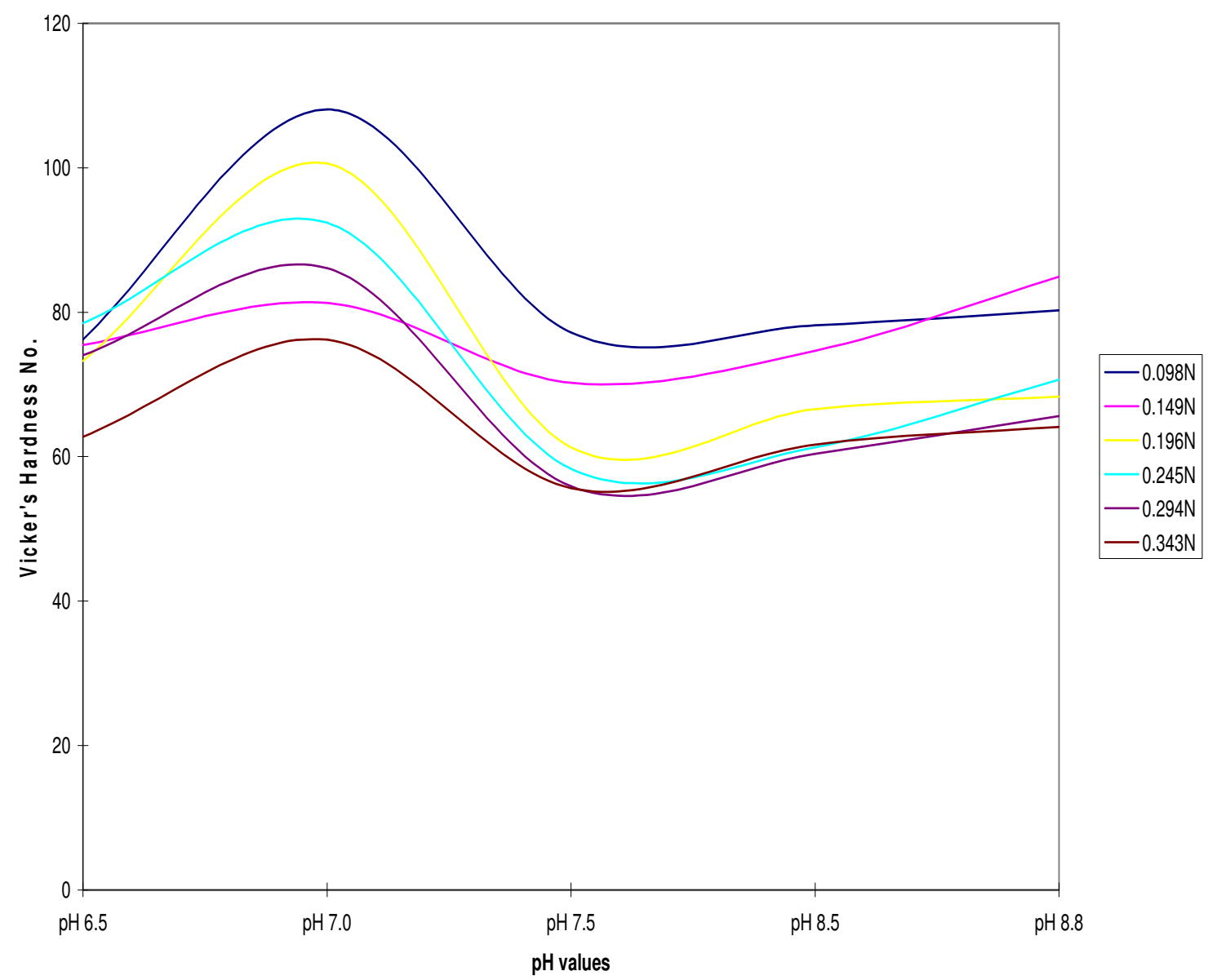

Fig. 3. Dependence of Vickers Hardness number at specific load on $\mathrm{pH}$.

Table 2. Orientation Hardness No. dependence of Calcite in air and in 2-propanol.

\begin{tabular}{|c|c|c|c|c|c|c|c|}
\hline \multicolumn{4}{|c|}{ Calcite in Air } & \multicolumn{4}{|c|}{ Calcite in 2-Propanol } \\
\hline Orientation & $0^{\circ}$ & $30^{\circ}$ & $60^{\circ}$ & Orientation & $0^{\circ}$ & $30^{\circ}$ & $60^{\circ}$ \\
\hline $\mathrm{X}^{-3 / 2}\left(\mathrm{x10} \mathbf{m}^{-4} \mathrm{~m}\right)$ & 3.77 & 2.90 & 3.10 & $\mathrm{X}^{-3 / 2}\left(\mathrm{x}^{-4}{ }^{-4} \mathrm{~m}\right)$ & 2.63 & 1.94 & 2.47 \\
\hline $\begin{array}{c}\text { Crack length } \\
\mathbf{X}_{(\mu \mathrm{m})}\end{array}$ & 52.2 & 43.8 & 45.8 & $\begin{array}{c}\text { Crack length } \\
\mathbf{X}_{(\mu \mathrm{m}}\end{array}$ & 41.0 & 33.5 & 39.4 \\
\hline $\begin{array}{c}\text { Hardness } \\
\text { Number }\end{array}$ & 10.21 & 14.43 & 13.26 & $\begin{array}{c}\text { Hardness } \\
\text { Number }\end{array}$ & 16.55 & 24.79 & 17.92 \\
\hline
\end{tabular}




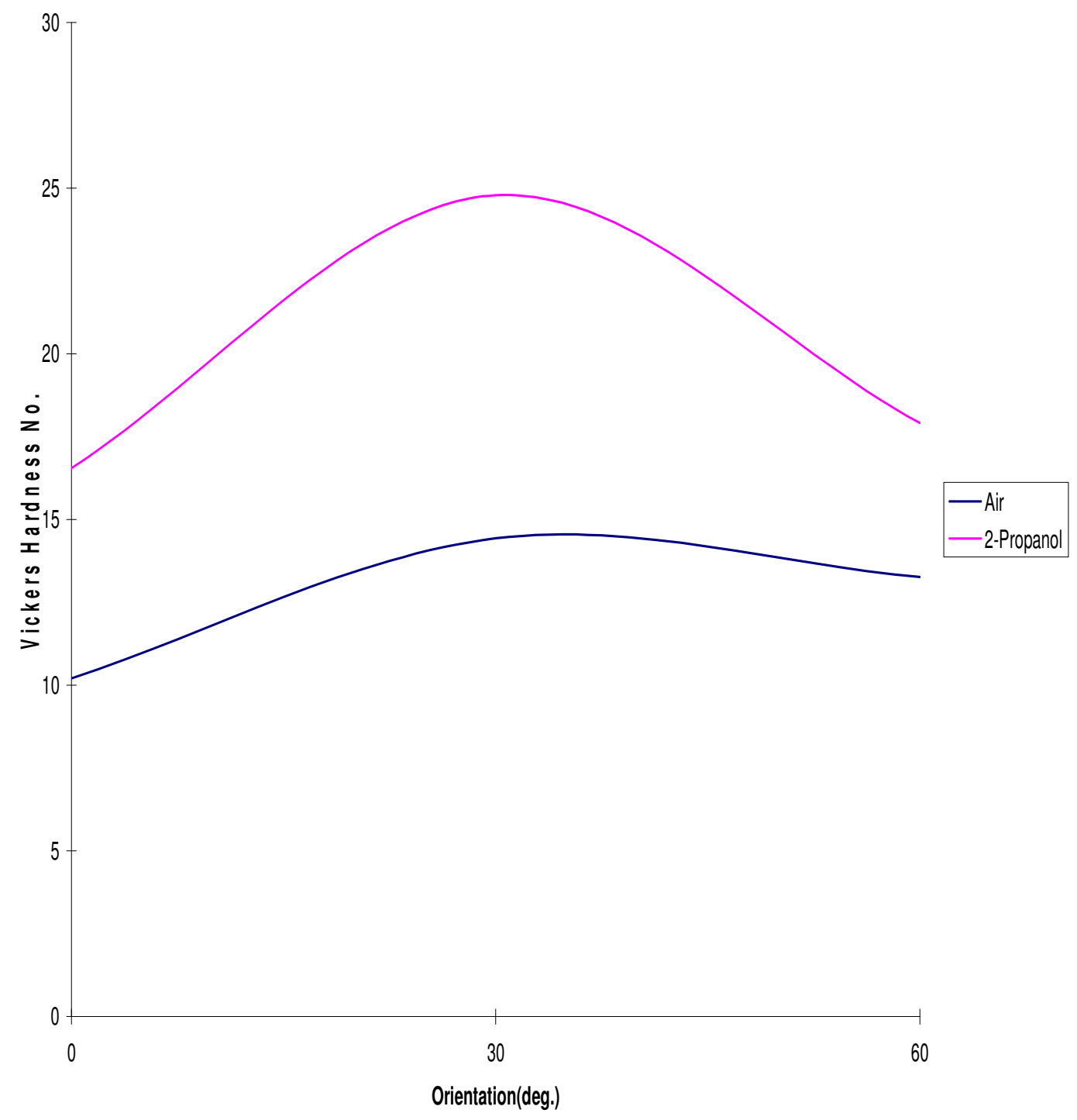

Fig. 4. Orientation dependence of hardness no. of Calcite in Air and 2-propanol.

A notable mechanism for Rebinder effect, in which changes in surface charge influences nearsurface plastic deformation of surfaces and thereby the hardness, was observed in this study as well [18].

This is as a result of some of the environments that facilitate flow in the near-surface region i.e. softens it, and also reduced fracture strength, while others do not facilitate flow in the near surface regions i.e. hardens it, and also increases the fracture strength.

At this point it is reasonable to suppose that a significant amount of plastic deformation necessarily occurs in a "flow-zone" immediately around the indenter edge. Since material in this 
zone cannot readily escape around the edge of the indenter, strain accumulates, rapidly exhausting the limited work-hardening capacity of the material.

The environment-sensitivity of dislocation mobility in Calcite, an ionic solid, appears consistent with the interpretation of the basic mechanism suggested earlier by Westwood et al [19]; electron transfer during chemisorptions causes changes in the electronic structure and electrostatic potential of the near surface region of the solid. In crystalline materials, this causes alterations in the state of ionisation of near surface dislocation and point defects; consequently, the electrostatic interactions between moving near-surface point defects and between dislocations, and intrinsic and extrinsic point defects, and between dislocations and lattice, are changed. Since these are the factors that control dislocation mobility (and hence hardness) in ionic materials, the near surface of such crystals is environment-sensitive [16].

\section{FRACTURE (MORPHOLOGY)}

Cracking in all the environments on the test surface occurred for the entire load from $0.1 \mathrm{~N}$ to $0.35 \mathrm{~N}$. The rectangular nature of the indents, denoting orientation dependence, suggests cleavage rather than conchoidal fracture. Median cracks were observed in Figure 1p. Lateral cracking stepped are seen in Figures $1 \mathrm{~b}, 1 \mathrm{c}$, and $1 \mathrm{j}$.

The relation in equation (2) was plotted and a least square-fit analysis of results undertaken as it can be observed in Figure 2. A linear plot was obtained for $\mathrm{P}-\mathrm{C}_{\mathrm{R}}{ }^{3 / 2}$ thus confirming the universal applicability of the relation in the estimation of $\mathrm{K}_{1} \mathrm{c}$ for crystals, as already reported for alumina [15] SiC [16] and Beryl [13].

$\mathrm{H}$ in the $(\mathrm{E} / \mathrm{H})$ in equation (2) was obtained by taking the averages of Vickers indentation diagonals " $\mathrm{d}$ " using the relations

$$
H=\frac{P}{2 \alpha^{2}}
$$

Where $\alpha=1 / 2 d$

An instance of peeling-off effect as a result of interaction of lateral cracks with environment is seen in Figure 1g. Sinking-in was observed for PH 8.8 and 6.5.

Calcite has a hardness profile that is orientation dependent in 2- Propanol, this is shown in Figure 4. The dependence of Critical stress intensity factor $\mathrm{K}_{1 \mathrm{C}}$ on $\mathrm{pH}$ is exhibited in a near sinusoidal form, with a minimum value at $\mathrm{pH} 7$, and peaks at $\mathrm{pH} 8.5$; this is shown also in Figure 5. 


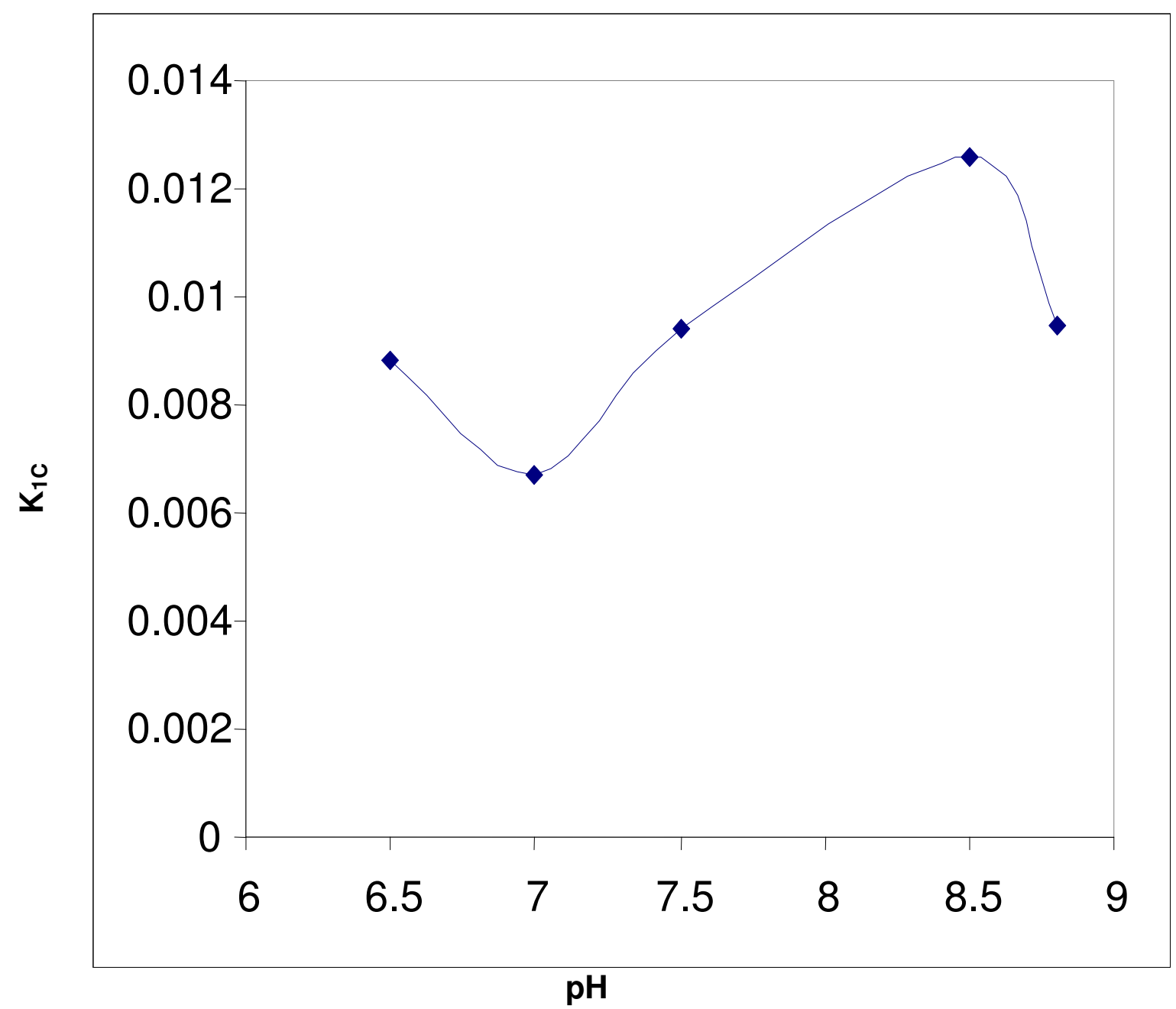

Fig. 5. $\mathrm{pH}$ dependence of Critical Stress Intensity factor $\mathrm{K}_{1 \mathrm{C}}$ in Calcite on $\{100\}$.

\section{CONCLUSION}

$\mathrm{K}_{1} \mathrm{c}$ values are found to be environment - dependent and that flow and fracture occur in calcite. Flow and fracture are anisotropic. The Vickers microhardness value demonstrates both orientation and environment dependence. This work interestingly has implication for faceting, polishing and other technological processes requiring surface and near surface materials transport. This latter obviously forms the basis for further work. 


\section{REFERENCES}

1. Pal T. And Kar T. 'Studies of Microhardness anisotropy and Young's modulus of nonlinear optical crystal I-arginine hydrochlorobromo monohydrate" Materials Letters 59(11); 1400, 2005

2. Adeoye M.O. and Adewoye O.O. "Investigation of hardness anisotropy in tourmaline, Journal of Minerals and Materials Characterization and Engireering, 3(2): 99, 2004

3. Adewoye O.O. and Agu J.I. "Knoop microhardness determination of the slip systems in beryl $\left[\mathrm{Be}_{3} \mathrm{Al}_{2}\left(\mathrm{SiO}_{3}\right)_{6}\right]$ " Journal of Materials Sci. 6:953, 1987

4. J. A. Jacobs \& T. F. Kilduff, Stress concentration and fracture toughness, Engineering Materials Technology (2001), p 436 - 441, Prentice Hall, Inc.

5. J. R. Pandya et al Bulleting of materials science (India) Vol. 5 No. 1 (March 1983) p 79 82.

6. B. J. Mehta, Cryst. Res. and Technol. (Germany) Vol. 17, No. 8 (1982) p 939 - 942.

7. O. O. Adewoye, G. R. Sawyer, J. W. Edington and T. F. Page, European research, office of the U. S. Army report no. DATA $37.74-c-1310$ (1974)

8. Robert E. Cuthrell - The influence of hydrogen on the deformation and fracture of the near surface region of solids: proposed origin of the Rebinder-Westwood effect, Journal of Materials Science, Volume 14, Number 3 / March, 1979612 - 618

9. S. V. Hainsworth and T. F. Page - Nanoindentation studies of the Chemomechanical effect in sapphire, Journal of Materials Science, Volume 29, Number 21 / January, 1994, 5529-5540

10. S. J. Bull and T. F. Page - Chemomechanical effects in ion-implanted MgO,J. Phys. D: Appl Phys. 22, 1989, 941-947

11. Honglin Zhu, Dale E. Niesz, Victor A. Greenhut, Robert Sabia - The effect of abrasive hardness on the chemical - assisted polishing of (0001) plane sapphire JMR.2005, Volume: 20:2, 504-520

12. B. R. Lawns, A. C. Evans and D. B. Marshall. J. Gmer. Ceram. Soc. 63 9-10 574 (1980)

13. O. O. Adewoye, J. Mater. Sci. Lett. 3(1984), p. 855-858

14. R. W. Armstrong and C. Wu, J. Am Ceram. Soc. 61, Nos. 3- 4 pp. 102-106 (1978)

15. S. S. Smith and B. J. Plekta, Indentation fracture of Single Crystals and Polycrystalline Alumina (1983) p 189 (Plenum Press, New York ed. RC Bradt A.G. Evans, D.P.H. HAsselman and F.F. Large)

16. O. O. Adewoye, in Fracture Mechanics of Ceramics edited by R.C. Bradt A. G. Evans, D.P.H. Hasselman and F. F. Large, Plenum Press New York (1983) p 107

17. George V. Chilinger, Harold J. Bissell, Rhodes W. Fairbridge Eds., Development in Sedimentology 9B, Carbonate Rocks, Physical \& Chemical spects, p.362-3

18. Alley David W, Devereux Owen F. Coolant $\mathrm{pH}$ of optimum Ceramic griding .I. Rebinder effect in polycrystalline aluminum oxide, Journal of Materials Sc. (J. mater.Sci.)(2002), vol.37no23, p 5135-5140 
19. A.R.C. Westwood et al, Relationship between Zeta Potential and dislocation mobility (1973), Martin Marietta Lab., Baltimore, Maryland 21227 USA 